\title{
Chapter 6 \\ Care of the Critically Ill Pediatric Sickle Cell Patient
}

\author{
Tolulope Rosanwo, Jennifer A. McArthur, and Natasha Archer
}

\section{Introduction and Chapter Overview}

Sickle cell disease (SCD) is the most common inherited genetic disease in the United States with 1 in 13 Americans of African descent found to be carriers (sickle cell trait) and an estimated 100,000 individuals living with the disease. The incidence of SCD in West and Central Africa is even more pervasive as 1000 babies with SCD are born daily, and 1 in 4 Africans in the regions with the highest incidence of SCD have the trait [1].

Sickle hemoglobin $(\mathrm{Hb} \mathrm{S})$ within the red blood cell (RBC) polymerizes under hypoxic conditions. Hb S polymerization distorts the cell's biconcave shape and characteristic flexibility, providing the main pathological bases of this disease, hemolysis and vaso-occlusion (Fig. 6.1). Occluded and damaged vasculature contributes to pan-organ damage impacting the cardiovascular, hepatic, splenic, musculoskeletal, neurological, renal, and pulmonary systems predominantly.

\footnotetext{
T. Rosanwo

Case Western Reserve University School of Medicine,

Cleveland, $\mathrm{OH}$, USA
}

\section{J. A. McArthur}

Department of Pediatrics, Division of Critical Care Medicine,

St. Jude Children's Research Hospital, Memphis, TN, USA

Medical College of Wisconsin, Milwaukee, WI, USA

e-mail: jennifer.mcarthur@stjude.org

N. Archer $(\bowtie)$

Department of Pediatric Hematology and Oncology,

Dana-Farber Boston Children's Cancer and Blood Disorders Center,

Harvard Medical School, Boston, MA, USA

e-mail: Natasha.Archer@childrens.harvard.edu 


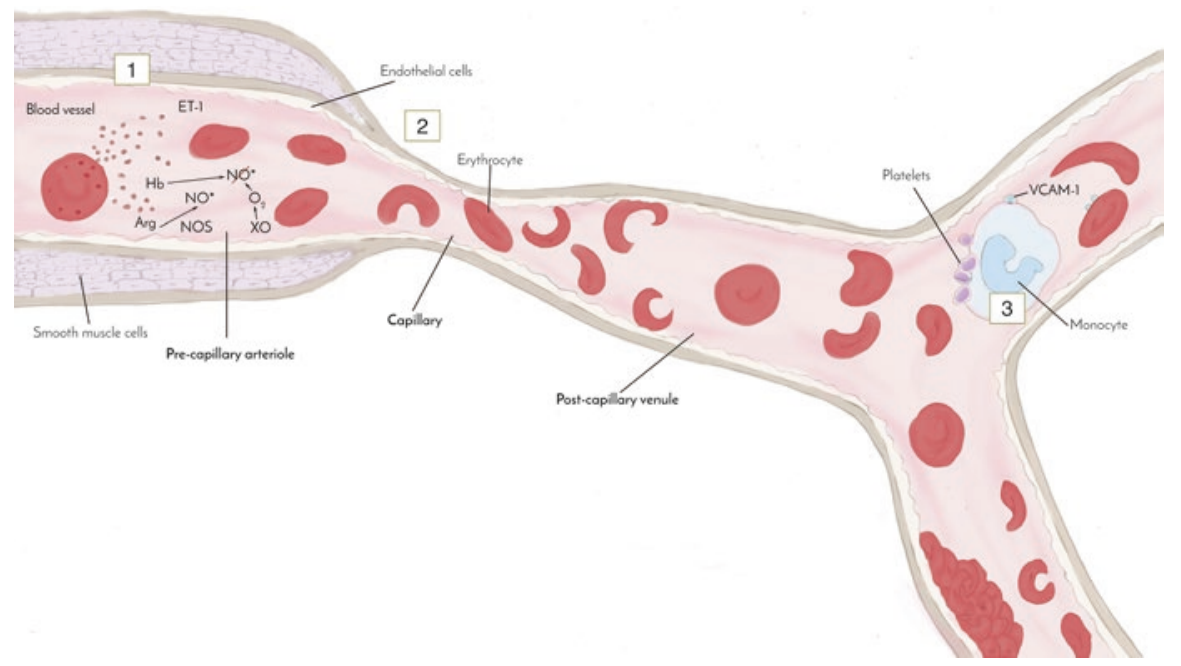

Fig. 6.1 The pathology of sickle cell disease. (1) Intracellular sickle hemoglobin (Hb S) polymerization contributes to the hallmark red cell deformation seen in SCD. Intravascular hemolysis releases hemoglobin, activating endothelin-1 (ET-1). ET-1 inactivates the production of nitric oxide (NO) from arginine, exacerbating vasoconstriction. (2) Inflexible sickled cells vaso-occlude capillaries resulting in ischemia and infarction. (3) SCD is an inflammatory state. Red cells adhere to platelet-monocyte aggregations via adhesion molecules like vascular cell adhesion protein 1 (VCAM-1) in vaso-occlusive episodes. Hydroxyurea, one of the two FDA-approved pharmacological treatments for pediatric sickle cell disease, reduces sickling via the upregulation of fetal hemoglobin production and the reduction of circulating leukocytes, reducing inflammation and vaso-occlusion)

SCD is a debilitating disorder, and all patients are at high risk of both sudden and deadly vaso-occlusive complications. The most common indication for intensive care unit (ICU) admission is acute chest syndrome (ACS) [1]. Shock, stroke, and multiple organ failure are also potential causes of critical illness (Fig. 6.2) [2, 3]. In the United States and Great Britain, pediatric SCD patients account for roughly $2 \%$ of pediatric ICU (PICU) admissions. Eight percent of SCD patients will require at least one ICU admission within an 8-year follow-up [4], and $13 \%$ of patients with ACS will require ICU admission and mechanical ventilation [5]. Even more alarming, the mortality of SCD patients admitted to the ICU can be as high as 44\% [6]. Timely admission to the ICU facilitates better outcomes for patients, and it is imperative for physicians to regard even apparently uncomplicated vaso-occlusive episodes as potentially life threatening.

This chapter will highlight the impact of SCD-related organ damage in a critically ill pediatric patient and outline evidenced-based strategies for management in the intensive care setting. 


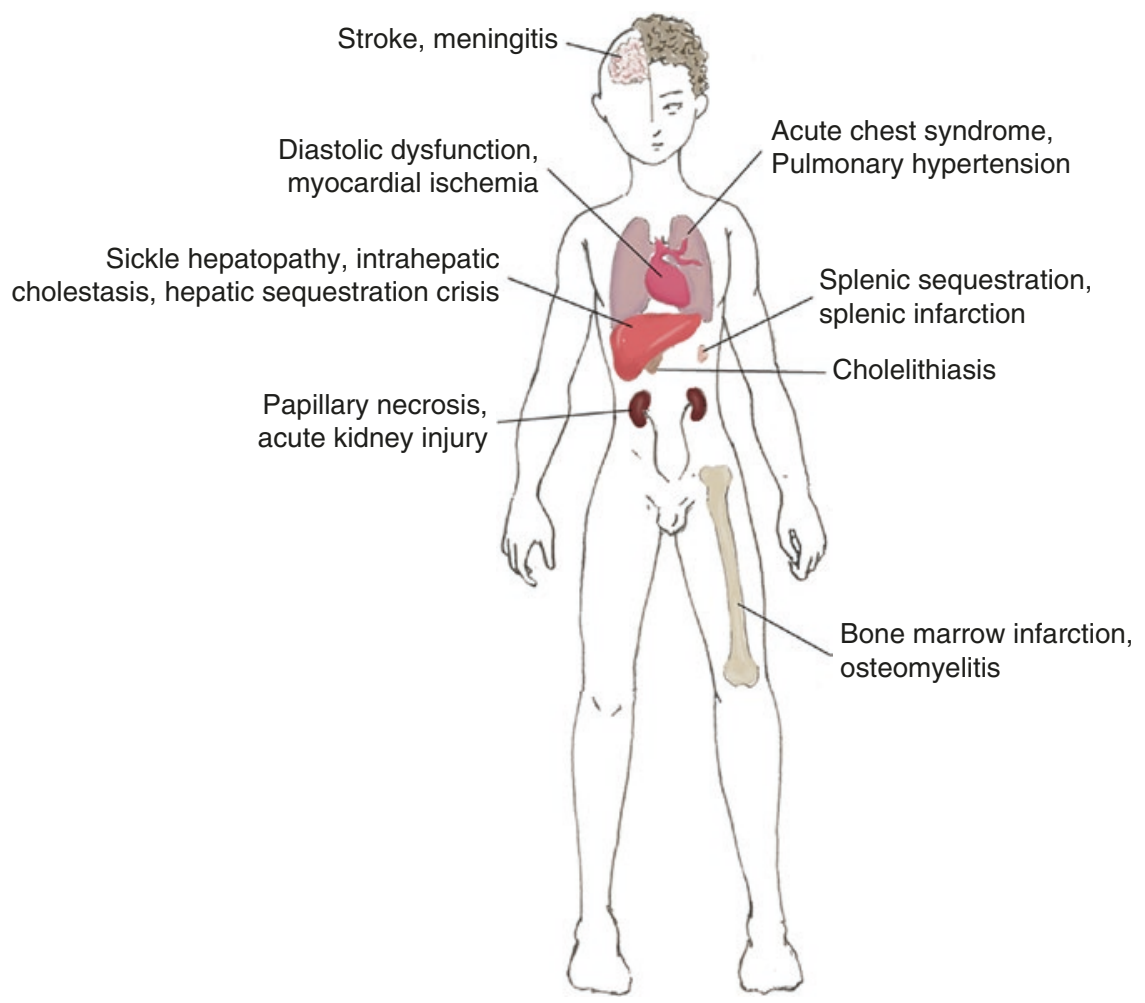

Fig. 6.2 Acute complications of sickle cell disease (Acute complications of SCD can impact nearly every organ system. Acute chest syndrome and stroke are leading causes of ICU admission. Each acute complication will be addressed in the chapter sections below)

\section{Cardiovascular Concerns}

$23.4 \%$ of SCD adult death at home or in the hospital is sudden [7]. This figure is not known in children, although pediatric patients with sickle cell trait alone have a 21-fold higher risk of sudden cardiac death than those with completely normal hemoglobin [8]. The cardiac concerns discussed below, particularly cardiomegaly, left ventricular dysfunction, arrhythmias, and pulmonary hypertension (PH), contribute to sudden cardiac death [9]. Appropriate management of the cardiac consequences of SCD will reduce this risk in the critical SCD ICU patient.

\section{Baseline Cardiovascular Pathology in SCD}

\section{Cardiomegaly and Left Ventricular Dysfunction}

The SCD patient's underlying anemia reduces their oxygen-carrying capacity despite increased baseline cardiac output [10]. Severe anemia correlates with ventricular dilation leading to both compensatory hypertrophy and increased left 
ventricular (LV) mass. The sustained elevated cardiac output contributes to the cardiomegaly seen in most sickle cell patients after 3 years of age [11]. Enlarged hearts despite usually normal coronary vasculature put children with lower hemoglobin levels at risk for induced ischemic ECG changes [12]. It is also to be noted that children with LV hypertrophy have lower average sleep and waking oxygen saturation. Sleep studies are informative predictors of cardiomegaly risk. An ACE inhibitor like enalapril can reduce cardiac remodeling in advanced cases. SCD patients are also prone to LV dysfunction although the link between vaso-occlusion and reduced ventricular contractility is not apparent.

\section{Cardiac Consequences of Iron Overload}

Twenty percent of children with SCA are regularly transfused to reduce their stroke and ACS risk. The regular supply of RBCs, "bags" of iron-containing hemoglobin can push patients into an iron-overloaded state with cardiac consequences. Free iron fuels the formation of reactive oxidative species (ROS), leading to lipid, protein, and DNA abnormalities. In this toxic state during which transferrin is fully bound to iron, non-transferrin bound iron (NTBI) enters cardiomyocytes as ferrous iron via L-type $\mathrm{Ca}^{2+}$ (voltage-dependent) channels. Iron accumulates in the epicardium, ventricular septum, papillary muscles, and ventricular wall.

Iron deposition begins first in the ventricular myocardium and then the atrial myocardium [10]. The accumulation clinically manifests as progressive cardiac dysfunction beginning with diastolic dysfunction followed by systolic dysfunction and heart failure [13]. First-degree heart block and supraventricular arrhythmias are also lethal consequences of cardiac iron toxicity [14].

Diagnosis via signs of cardiotoxicity measured by ECG, echocardiogram, and radionucleotide angiography are not suggested as these are not apparent until late/ severe stages of iron overload. T2* magnetic resonance for cardiac iron, however, is a noninvasive way to detect iron deposition in subclinical patients.

\section{ICU Concerns}

High-output cardiac failure and high-grade diastolic dysfunction and $\mathrm{PH}$ are the most common cardiac concerns in the ICU in adult patients but are usually less severe in pediatric patients.

\section{Diastolic Dysfunction}

Both diastolic dysfunction and $\mathrm{PH}$ are poor prognostic indicators for SCD ICU patients. In a cohort of 107 patients between 3 and 18 years of age, 11.2\% had PH, a lower percentage than found in adults (32\%), and grade I diastolic dysfunction 
was seen in the majority of patients [11, 15]. Like cardiomegaly, diastolic dysfunction in children is elevated in patients with lower sleeping and waking oxygen desaturation [16]. Non-transfused patients often have a larger LV mass than transfused patients. LV end-diastolic diameter, end-systolic diameter, and late-diastolic mitral flow are also increased.

\section{Pulmonary Hypertension}

Pulmonary hypertension (PH) is a major cause of early mortality in SCD. Those diagnosed have been seen to have a tenfold greater risk of death [15]. Intravascular hemolysis, a hallmark of SCD, releases hemoglobin and arginase into the plasma, and these proteins are taken up by nitric oxide (NO) and L-arginine, its precursor. Subsequent reduced bioavailability of NO exacerbates baseline vaso-occlusion in the pulmonary vasculature, as capillaries fail to dilate. Endothelin-1, a vasoconstrictor, is also elevated in SCD patients during vaso-occlusive episodes and may contribute to PH severity.

Patients particularly at risk of $\mathrm{PH}$ have high rates of chronic intravascular hemolysis evidenced by low steady-state hemoglobin levels, elevated lactic dehydrogenase (LDH), bilirubin, and reticulocyte counts.

PH evaluation and diagnosis via echocardiogram has low sensitivity with a positive predictive value of about $25 \%$ (21). This finding might contribute to the underreporting of $\mathrm{PH}$ in $\mathrm{SCD}$ patients. To improve noninvasive diagnosis, measuring the $\mathrm{N}$-terminal fragment of brain natriuretic peptide (NT-proBNP) has been encouraged [17]. NT-proBNP is a cardiac ventricular prohormone made in response to myocyte stretch. BNP, the downstream hormone, facilitates systemic vasodilation. NT-proBNP levels are elevated in $\mathrm{PH}$ and are also an independent predictor of mortality. In pediatric patients, NT-proBNP is strongly correlated with high reticulocyte count [17].

Hydroxyurea and chronic exchange transfusion are long-term management treatments for pulmonary hypertension [18]. However, in the acute setting of right ventricular heart failure, exchange transfusion should also be initiated. In addition, case reports have noted that some patients have responded to nitric oxide, endothelin receptor antagonists, or prostanoids [19].

\section{Myocardial Ischemia}

Autopsy reports indicate that myocardial infarction (MI) is often underdiagnosed in patients with SCD [20]. MI must be considered in any patient presenting with chest pain as it may be clinically indistinguishable from more common causes of chest pain such as acute chest syndrome, rib infarction, or epigastric pain [10].

MI is underdiagnosed perhaps because the mechanism of MI in SCD is not well understood. Reduced oxygen content due to underlying anemia and abnormal 
myocardial microvasculature both could contribute to fibromuscular dysplasia of small vessels and ischemic changes. Abnormal platelets seen in SCD may also release thromboxane resulting in vasospasm, infarct, and necrosis.

The nonspecific ST-T wave changes existing in some SCA patients make ECG often unhelpful in MI diagnosis. However, in one study, a useful pediatric scoring system for MI which used ECG in early detection of MI was found to be helpful [21]. Cardiac enzymes may also be low in patients with SCD having an MI due to cardiomyocyte death secondary to apoptosis instead of necrosis. Given the lack of sensitivity of the traditional MI workup in patients with $\mathrm{SCA}$, cardiac magnetic resonance has been proposed to detect microvascular disease in symptomatic patients. However, it seems more practical to use echocardiogram to look for regional wall motion abnormalities as they are often normal at baseline in SCD patients even in patients that have a baseline abnormal EKG [22].

MI management must reduce ischemia via standard medical approaches and implement reperfusion of myocardium via thrombolysis or mechanical revascularization. In addition, exchange transfusion has also had a positive effect in MI cases in patients with SCD $[23,24]$. Keeping in mind that a higher hemoglobin transfusion threshold may be beneficial in all MI patients, simple transfusion may be not only faster but clinically more helpful. In the setting of right heart failure, inhaled nitric oxide (NO) may be useful as a vasodilator and inhibitor of platelet activation; however, there is no clinical data to support this.

\section{Hepatic and Biliary Concerns}

Sickle cell-associated hepatic and biliary complications are numerous and can be significant (Table 6.1). Complications secondary to sickling as well as coexisting conditions will be addressed in this section.

\section{Hepatobiliary Clinical Syndromes Secondary to Sickling}

\section{Acute Sickle Hepatic Crisis}

One in ten SCD patients will have an acute sickle hepatic crisis. Vaso-occlusive obstruction of liver sinusoids results in ischemia, which presents clinically with right upper quadrant (RUQ) pain, fever, nausea, jaundice, and hepatomegaly [25]. A patient's alanine transaminase (ALT) and/or aspartate amino transferase (AST) levels may be elevated but not in every case [25]. Patients should be well hydrated with intravenous fluids and treated with analgesia if needed. 
Table 6.1 Hepatic and biliary complications of sickle cell disease

\begin{tabular}{|c|c|c|c|c|}
\hline & $\begin{array}{l}\text { Secondary to } \\
\text { sickling versus } \\
\text { coexisting } \\
\text { condition }\end{array}$ & Etiology & Presentation & Management \\
\hline $\begin{array}{l}\text { Acute hepatic } \\
\text { crisis }\end{array}$ & Secondary & $\begin{array}{l}\text { Vaso-occlusion of } \\
\text { liver sinusoids }\end{array}$ & $\begin{array}{l}\text { RUQ pain, fever, } \\
\text { nausea, jaundice, } \\
\uparrow A L T / A S T\end{array}$ & Hydration, analgesia \\
\hline $\begin{array}{l}\text { Intrahepatic } \\
\text { cholestasis }\end{array}$ & Secondary & $\begin{array}{l}\text { Sickled cells } \\
\text { adherence to } \\
\text { hepatic } \\
\text { endothelium }\end{array}$ & $\begin{array}{l}\text { RUQ pain, } \\
\text { low-grade fever, } \\
\text { tender } \\
\text { hepatomegaly, } \\
\text { jaundice } \\
\uparrow \text { bilirubin }\end{array}$ & PRBC transfusion \\
\hline $\begin{array}{l}\text { Hepatic } \\
\text { sequestration } \\
\text { crisis }\end{array}$ & Secondary & $\begin{array}{l}\text { Sickled cells } \\
\text { trapped in liver } \\
\text { vasculature }\end{array}$ & $\begin{array}{l}\text { RUQ pain, } \\
\text { hepatomegaly, } \downarrow \\
\text { hematocrit }\end{array}$ & Simple transfusion \\
\hline $\begin{array}{l}\text { Hepatic Iron } \\
\text { overload }\end{array}$ & Coexisting & Transfusion & & Iron chelation \\
\hline Viral hepatitis & Coexisting & Hep A, B, C, E & & \\
\hline $\begin{array}{l}\text { Acute } \\
\text { cholecystitis }\end{array}$ & Coexisting & Hemolysis & $\begin{array}{l}\text { Asymptomatic, } \\
\text { RUQ }\end{array}$ & Exchange transfusion \\
\hline $\begin{array}{l}\text { Pyogenic liver } \\
\text { abscess }\end{array}$ & Coexisting & $\begin{array}{l}\downarrow \text { GI integrity, } \\
\uparrow \text { enteric } \\
\text { microorganisms }\end{array}$ & $\begin{array}{l}\text { Fever, jaundice, } \\
\text { tender } \\
\text { hepatomegaly }\end{array}$ & $\begin{array}{l}\text { Drain abscess, } \\
\text { broad-spectrum } \\
\text { antibiotics, analgesia, } \\
\text { hydration }\end{array}$ \\
\hline $\begin{array}{l}\text { Autoimmune } \\
\text { hepatitis }\end{array}$ & Coexisting & Unknown & $\begin{array}{l}\uparrow A L T / A S T, \\
\text { jaundice }\end{array}$ & $\begin{array}{l}\text { Prednisolone, } \\
\text { azathioprine, } \\
\text { ursodeoxycholic acid }\end{array}$ \\
\hline $\begin{array}{l}\text { Focal nodular } \\
\text { hyperplasia }\end{array}$ & Coexisting & $\begin{array}{l}\text { Vascular anomaly } \\
+ \text { vaso-occlusion }\end{array}$ & $\begin{array}{l}\text { Distended } \\
\text { abdomen, tender } \\
\text { hepatomegaly }\end{array}$ & Surgical resection \\
\hline
\end{tabular}

\section{Intrahepatic Cholestasis}

Intrahepatic cholestasis is a severe variation of hepatic crisis. The pathological mechanism underlying this condition is largely unknown, but it is suspected that sickled cells adhere to the hepatic endothelium, facilitating the vaso-occlusive state, tissue infarction, and then liver dysfunction [26]. The hypoxic damage that occurs as a result leads to both hepatocyte ballooning and intracanalicular cholestasis.

The presentation of intrahepatic cholestasis is nonspecific with acute RUQ pain, low-grade fever, hepatomegaly tender with palpation, jaundice, and icteric sclera. Upon further investigation, patients will have high bilirubin levels (direct $>$ indirect) and, in the progression to hepatic failure, coagulopathy.

Other potential causes with a similar clinical presentation such as biliary obstruction, sequestration crisis, viral hepatitis, medication-induced toxicity, autoimmune 
disease, and iron overload must be excluded. Diagnosis via ultrasound should reveal an enlarged liver with thickened gallbladder wall and no gallstones. Magnetic resonance cholangiopancreatography (MCRP) should detect periportal thickening in the absence of intra- and extrahepatic biliary duct dilation.

Liver biopsy is associated with serious complications in SCD patients and should be avoided [27]. Histology would reveal sickle thrombin in liver sinusoids, Kupffer cell hypertrophy, centrilobular necrosis, and bile stasis.

Packed red blood cell (PRBC) transfusion followed by manual exchange transfusion should be initiated at the onset of treatment with the goal to reduce sickle hemoglobin to below 30\% [28]. Liver transplantation is indicated in patients with fulminate failure [29] although recurrence of sickle cell hepatopathy is possible [27]. Fresh frozen plasma can also be used to correct coagulopathy [25]. Coagulopathy is common and worsens as the liver undergoes necrosis. The data on whether bilirubin can be used to predict outcomes is inconclusive [30, 31]. Progression to severe liver disease is possible even if not found on presentation. Therefore patients should be monitored closely until bilirubin levels begin to decrease.

\section{Hepatic Sequestration Crisis}

Hepatic sequestration crisis is a deadly hepatic pathology in SCD patients. When sickled RBCs are trapped or "sequestered" in the liver vasculature, the reduced levels in circulation exacerbate the anemic state. Patients present with RUQ pain, increasing hepatomegaly, and rapidly declining hematocrit levels. Of note that liver function enzymes may be at baseline levels.

The main goal of management is to replenish the blood volume to treat hypovolemia and prevent shock [32]. Treatment typically begins with simple transfusion to the absolute minimum levels to treat symptomatic anemia ( $5 \mathrm{cc} / \mathrm{kg}$ for children).

"Autotransfusion" or "reverse sequestration" is a phenomenon when sequestered blood cells re-enter the circulation causing hyperviscosity syndrome. Death secondary to hyperviscosity syndrome is a result of hypervolemia, hypertension, heart failure, and/or intracerebral hemorrhage [33]. Therefore, it is critically important to closely monitor hemoglobin levels in hepatic sequestration patients. If the hemoglobin concentration rises above $11 \mathrm{~g} / \mathrm{dl}$, phlebotomy should be considered.

\section{Hepatobiliary Dysfunction Secondary to Coexisting Conditions}

\section{Hepatic Consequences of Iron Overload}

Steady-state ferritin levels that are comparatively very low (less than $1000 \mathrm{ng} / \mathrm{ml}$ ) or very high (greater than $3000 \mathrm{ng} / \mathrm{ml}$ ) can be used to estimate the severity of iron overload [34]. Excess iron in chronically transfused patients is deposited in the reticuloendothelial cells and is visually determined via T2 magnetic resonance for 
hepatic iron. In these instances, iron chelation increases excretion of iron. When left untreated, iron accumulation in the liver parenchyma results in hemochromatosis and cirrhosis.

\section{Viral Hepatitis}

The incidence of hepatitis A, B, and E is low in the sickle cell population. Hepatitis $\mathrm{C}$ had been increased in comparison to the general population especially in chronically transfused patients, but that has declined with blood donor screening for the virus $[35,36]$.

\section{Acute Cholecystitis}

Hemolysis, a key component of SCD pathology, necessitates the removal of bilirubin from circulation. As a result, almost half of all patients with SCA will have developed calcium bilirubinate gallstones by their 18th birthday [37]. Data suggests that most SCD patients with cholelithiasis, even those that are asymptomatic, should undergo cholecystectomy. Emergent procedures are associated with a higher risk of mortality [38]. Increasing the hemoglobin to a goal of $10 \mathrm{~g} / \mathrm{dl}$ as opposed to more aggressive transfusion to reduce $\mathrm{Hb} \mathrm{S}$ to less than $30 \%$, is recommended [39].

\section{Pyogenic Liver Abscess}

Hepatic infarction is common in SCD as it is detected in 34\% of autopsies of patients with the disease [40]. Pyogenic liver abscess, a potential consequence of infarct, arises after the infarcted tissue facilitates mucosal capillary thrombosis. Gastrointestinal integrity is compromised, and commensal enteric microorganisms overgrow [41]. Other causes of increased risk of pyogenic liver abscess are secondary to functional asplenia or impaired opsonin phagocytic function seen in complement pathways [41].

Patients appear very ill, presenting with fever, jaundice, and tender hepatomegaly. Abdominal radiograph (elevation of the right diaphragmatic cupola) as well as ultrasound (abscess in the right hepatic lobe) is useful for diagnosis. To avoid sepsis and rapid decline, the abscess must be drained carefully with broad-spectrum antibiotics administered. IV fluids as well as appropriate analgesics are also necessary in management [42].

\section{Autoimmune Hepatitis}

In a single study from 1999 to 2015, 17\% of pediatric SCD patients with hepatic dysfunction were diagnosed with autoimmune liver disease [43]. These patients, often female, presented with increased liver enzymes and progressive jaundice. 
Patients can also present with acute hepatitis and acute liver failure. Autoimmune hepatitis is difficult to diagnose but is suspected in patients with elevated ALT/AST, positive autoantibodies, hypergammaglobulinemia, and interface hepatitis with histological evidence of portal plasma cell infiltrates without evidence of other disease. Young patients have achieved full remission with treatment including prednisone, azathioprine, and ursodeoxycholic acid [43].

\section{Focal Nodular Hyperplasia}

Although the etiology is unclear, it is suspected that SCD patients with an underlying vascular anomaly such as an arteriovenous malformation in combination with vaso-occlusion are at risk for focal hyperplasia of the liver as the ischemic tissue regenerates [44]. These patients present with distended abdomens and tender hepatomegaly. Diagnosis can be made via liver radionuclide scans in which a significant defect in liver filling is apparent. Ultrasound can detect the mass, while selective arteriography can detect both a mass and its blood supply.

If the mass is providing symptomatic pressure on internal organs and there is internal bleeding caused by abdominal trauma or significant discomfort, surgical resection is an appropriate treatment. Uncontrollable bleeding and blood loss resulting in death is a risk of this intervention [44].

\section{Hemodynamic Concerns}

\section{Thromboembolism in Sickle Cell Disease}

SCD is a hypercoagulative state [45]. The prevalence of pulmonary embolism (PE) in hospitalized patients is more than three times higher than in racially matched controls [46]. PE, normally presenting in middle-aged to older adults (average age 57 years), can also occur in younger (average age 28 years) SCD patients [46].

\section{Risk Factors Secondary to Sickling}

SCD is a disease of both RBC and endothelial dysfunction, key drivers of the hypercoagulable state. Structural changes in the sickled RBC membranes expose phosphatidylserine, which degrades lipids, inactivates coagulation proteins, and creates oxidative stress. Antiphospholipid antibodies are common in SCD patients, increasing their risk of thrombotic events [47]. 


\section{Risk Factors Secondary to Traditional Causes}

Venous thromboembolism, which is more common in severe disease, is associated with increased mortality [48]. Deep vein thrombosis prophylaxis is recommended in adult hospitalized patients, but there is no standard practice for children. Pediatric SCD patients who have higher risk of venous thromboembolism (VTE) may undergo prophylactic pharmacologic therapies especially if in a critical care setting, mechanically ventilated, hospitalized for 5 days or more (particularly if postpubertal), fighting systemic infection, using oral contraception, and immobile [49-52]. Low molecular weight heparin may be advantageous in this patient population as the response is highly predictable, does not require IV access (as this may be difficult in SCD patients), and does not cross the placenta (if the patient is pregnant).

\section{Splenic Concerns}

The spleen's involvement in SCD pathology has been closely studied. The spleen is often rendered afunctional in SCD patients by 10 years of age, if not earlier, secondary to splenic infarction [37]. Patients with homozygous hemoglobin SS disease are at the greatest risk of functional asplenia, while half of compound heterozygotes maintain splenic function. As the patient becomes functionally asplenic, the risk of infection by encapsulated organisms such as Haemophilus influenzae and Streptococcus pneumoniae increases. In much of the resource-limited countries of the world impacted by SCD, the leading cause of death in children is infection. Splenic concerns of particular note in the pediatric SCD ICU patient are sepsis as a result of serious bacterial infection and splenic sequestration crisis.

\section{Splenic Sequestration Crisis}

Splenic sequestration is a consequence of vaso-occlusion in the spleen in one third of young children with hemoglobin SS disease usually between 6 months to 2 years of age $[53,54]$. This crisis requires blood flow to the spleen, putting young children with hemoglobin SS disease at higher risk than adults. RBCs pool in occluded blood vessels resulting in a systemic drop in hemoglobin and blood volume. Shock and death occur as a result.

Patients at risk include those with auto-infarcted spleens to the point of fibrosis. The risk is also elevated in patients with past parvovirus B19 infection [55]. Upon examination, patients present with a rapidly enlarging spleen, decreased hemoglobin count, and reticulocytosis [56]. 
Transfusion of packed RBCs is necessary to raise hemoglobin to previous steadystate level and decrease $\mathrm{Hb} \mathrm{S}$ so that blood begins to flow again resulting in autotransfusion of trapped splenic blood. Avoid saline infusion or the expansion of plasma before blood is available, as this is likely to lead to heart failure. Ten to fifteen percent of patients die as a result of splenic sequestration, often prior to transfusion [53, 54]. Therefore, timely transfusion following diagnosis is paramount. Although mortality risk is the greatest for a patient during their first sequestration crisis, up to $50 \%$ of patients not splenectomized will have a repeated crisis [54]. Therefore, most clinicians will recommend splenectomy once the patient is stable and if they are already 5 years of age.

\section{Sepsis}

Fever in any child with SCD is a cause for concern and may be the only presenting symptom in sepsis. While viral causes are common, functional asplenia puts children with SCD at increased risk of bacteremia and sepsis. Pneumonia is the most common infection leading to sepsis in children with SCD; other serious causes include urinary tract infection, osteomyelitis, and meningitis [57, 58]. Broadspectrum antibiotics such as ceftriaxone or cefotaxime should be used in febrile patients. Vancomycin must be added if bacterial organisms are found in CSF fluid.

\section{Musculoskeletal Concerns}

Infarcts within the bone marrow are a major cause of pathology of SCD and classic precipitant of pain crisis. Poor blood supply increases the risk of avascular necrosis and joint damage in adult patients. Osteomyelitis, secondary to bacterial infection, is less common in adults and more common in children. Additionally, in younger patients and adults, fat embolism syndrome (FES) can be a serious complication of bone marrow necrosis.

\section{Fat Embolism Syndrome}

In patients without infection, FES contributes to $9 \%$ of acute chest syndrome (ACS) cases in children and adolescents with previously "mild" disease [59]. Necrotic bone marrow precipitates the release of fat globules into venous circulation. Patients often present with a history of mild disease with a seemingly uncomplicated vasoocclusive crisis (VOC) and at times thrombocytopenia. This is then followed by a rapid decline resulting to respiratory failure, altered mental status, and/or coma. Exchange transfusion should be implemented as soon as fat embolism syndrome is suspected as more than half of diagnoses occur at autopsy [59]. 


\section{Neurological Concerns}

Cerebrovascular incidents occur in up to $11 \%$ of SCD patients under 20 years of age - particularly those with hemoglobin SS disease and those that have not been screened with transcranial Doppler [60]. In most pediatric cases, ischemic stroke predominates over hemorrhagic stroke, although hemorrhagic stroke risk begins to increase in the late teens [60]. The key challenge in managing stroke in this population is in discerning stroke from other cerebrovascular manifestations of SCD mainly migraines, meningitis, cerebral malaria, and seizure disorder.

\section{Initial Management of Possible Stroke}

The initial treatment of a possible cerebrovascular incident is guided by presenting symptoms. When suspecting acute ischemic stroke, instead of a hemorrhagic event, simple and/or exchange transfusion should be implemented [61]. If a patient presents with fever and acute neurologic findings, treatment for bacterial infection is essential until meningitis is ruled out via differential diagnosis. Patients with bacterial meningitis often present with septic features. It is of note that fever can be a presenting symptom of stroke.

\section{Diagnosis}

Standard clinical and neuroimaging are usually satisfactory in the diagnosis of stroke. CT scan is adequate in children to diagnose ischemic stroke, but MRI is more sensitive in that it excludes other diagnoses of cerebrovascular manifestations. Children under 8 years of age may require sedation for MRI imaging. Magnetic resonance angiography (MRA) or CT angiography can be used to determine the existence of large vessel arteriopathy to exclude aneurysm [62]. If cerebral venous sinus thrombosis is suspected, MRI with magnetic resonance venography (MRV) is sensitive [63].

Baseline laboratory testing is critical in the diagnosis and management of a cerebrovascular manifestation of SCD. A complete blood count, reticulocyte count, as well as sickle hemoglobin percentage are informative. Blood cross-matching is needed for transfusion therapy. Coagulation studies as well as a basal metabolic panel are necessary to rule out other clinical phenotypes such as hypoglycemia.

\section{Ischemic Stroke}

While managing a patient with ischemic stroke, it is important to protect the airway from aspiration and maintain oxygen saturation at 95\% [64]. It is important to keep patients calm and comfortable. Further cerebral ischemia occurs via vasoconstriction 
in hyperventilating and crying patients. Similar to management of traumatic brain injury, cerebral perfusion pressure should be maintained by ensuring adequate blood pressure, normoglycemia should be the goal, and fever should be avoided. Normal carbon dioxide levels should be maintained to avoid decreased cerebral perfusion seen with hyperventilation or increased intracranial pressure seen with hypercarbia. Patients should be hydrated with isotonic saline (1.25-1.5 normal rate). Hypotonic saline will exacerbate cytotoxic cerebral edema and should be avoided [64].

Simple transfusion to the patient's baseline should be done carefully to avoid hyperviscosity syndrome and transitioned to exchange transfusion [64]. To date, there are no randomized clinical trials comparing transfusion to other interventions. However, it is suspected that transfusion reduces the $\mathrm{Hb} \mathrm{S}$ and hypoxemia facilitating the vaso-occlusive state. It has been found that recurrent strokes are reduced in children receiving exchange transfusion as opposed to only simple transfusion [65].

Anticoagulation is generally not recommended in treatment of ischemic stroke. However, as SCD is a hypercoagulable state, prophylactic anticoagulation may be appropriate in the event of arterial dissection, cerebral sinus thrombosis, or thromboembolism following a hemorrhagic episode [64].

\section{Hemorrhagic Stroke}

Hemorrhagic stroke, more commonly seen in adult patients, impacts $3 \%$ of patients with SCD, patients under 20 years of age [60]. In the event of a hemorrhagic stroke, management is dependent on the etiology whether it be ischemic transformation, subarachnoid hemorrhage secondary to aneurysm, or intraventricular hemorrhage.

\section{Ischemic Transformation}

Ischemic transformation should be managed similarly to the typical intracerebral hemorrhage. Anticoagulation must be terminated. Platelet transfusion should be implemented if needed to keep platelet counts above 100,000 cells per microliter.

\section{Subarachnoid Hemorrhage}

Subarachnoid hemorrhage is often secondary to aneurysm. Management should focus on maintaining blood pressure at normal values and providing the appropriate analgesia. If intracranial pressure is too great and ventriculostomy is scheduled, transfusion is recommended prior to the procedure [66]. 


\section{Intraventricular Hemorrhage}

The patients at risk of intraventricular hemorrhage are those who present with a subarachnoid hemorrhage which spreads into the ventricles [67] or previously had an ischemic stroke, months to years prior to this event [68]. Hemorrhage into the third ventricle or cerebral aqueduct is often detected late in its course. Ventricular drainage may be warranted.

\section{Renal Concerns}

Sickle cell nephropathy (SCN) begins in childhood and can eventually progress into renal failure [69]. Before a patient reaches 10 years of age, glomerular changes are apparent in even asymptomatic children with SCD.

\section{Baseline Renal Pathology in SCD}

The kidney's natural hyperosmolar, acidotic, and hypoxic environment is a prime site of further complication in SCD - particularly in the vasa recta capillaries. There, microthrombotic infarction and extravasation of blood into the renal medulla can occur. The natural history of SCN is often progressive. The repetitive infarction of the renal medulla first leads to hyposthenuria (secretion of dilute urine with a low specific gravity in comparison to blood plasma) in infancy to isosthenuria (excretion of urine with specific gravity equivalent to blood plasma) by adolescence. Papillary infarcts are responsible for renal papillary necrosis, which presents with painless hematuria (Fig. 6.3).

\section{Acute Kidney Injury}

Acute kidney injury (AKI) is common in hospitalized SCD patients. In one cohort of patients admitted with ACS, AKI occurred in $8 \%$ children [70]. In another cohort of children admitted with vaso-occlusive crisis, 50\% developed AKI [69]. Three quarters of vaso-occlusive episodes are compounded by acute multiorgan failure, and hemodialysis is a necessary treatment in 19\% of these episodes [2].

Risk factors for AKI depend on the type of kidney injury: prerenal, intrinsic, or postrenal. In children, prerenal and intrinsic causes are most common as repeated bouts of vaso-occlusive crisis; volume depletion secondary to hyposthenuria and the use of NSAIDs contribute to AKI [71]. 


\section{Infancy}

- Hyperfiltration, hypertrophy, hyposthenuria

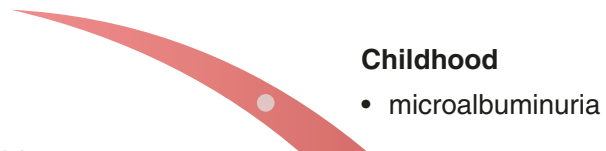

Any age

- hematuria, acute kidney injury

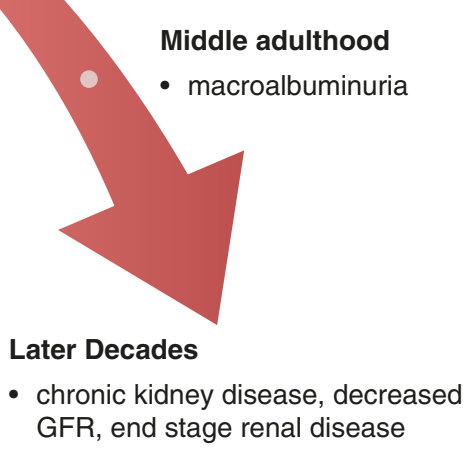

Fig. 6.3 Natural history of sickle cell nephropathy (SCN) (Sickle cell nephropathy (SCN) begins in childhood and progresses in severity to adulthood. While hematuria and acute kidney injury can occur at any age, hyperfiltration is seen in early life, while chronic kidney disease and end-stage renal disease are typically seen in the later decades of life)

\section{Prerenal AKI}

Hyposthenuria, which begins often in infancy, results in intravascular volume depletion facilitating prerenal injury.

\section{Intrinsic AKI}

Direct damage to the kidney via rhabdomyolysis, infection, NSAID use, sepsis, drug-induced nephrotoxicity (see "Iatrogenic Concerns" section), renal vein thrombosis, and hepatorenal syndrome results in intrinsic kidney disease.

\section{Postrenal AKI}

Papillary necrosis is a rare but possible cause of postrenal AKI. Thrombi, blocking the urinary tract, is a risk factor for this phenomenon. 


\section{Pulmonary Concerns}

Since the introduction of the pneumococcal conjugate vaccine in 2000, pediatric SCD-related mortality in the United States has shifted from predominantly infection to mortality risks seen in adult patients such as acute chest syndrome (ACS) and stroke [72]. ACS is the most common cause of ICU admission and death with mortality rates ranging from $1.8 \%$ to $25 \%$. Pulmonary hypertension $(\mathrm{PH})$, asthma, and restrictive lung disease are additional compounding factors leading to poor ICU outcomes in SCD patients. In this section, ACS, the most severe pulmonary concern, will be discussed in detail.

\section{Precipitating Factors}

Isolated and seemingly uncomplicated vaso-occlusive crisis is a key precipitating factor of ACS in hospitalized sickle cell patients [5]. Infection, pulmonary vascular obstruction by pulmonary arterial thrombi and fat emboli, and chest wall pain crisis precipitating alveolar hypoventilation also contribute to ACS onset. However, in $40 \%$ of cases the precipitating cause is known [5].

\section{Diagnosis}

Chest radiograph or CT scan revealing alveolar consolidation in lower zones is often indicative of ACS in addition to one or more of these signs symptoms: chest pain, fever, increased work of breathing, or hypoxemia relative to baseline $[5,73]$. Children with severe disease should undergo echocardiogram to assess for intervenable $\mathrm{PH}$ and/or cor pulmonale.

\section{Complications and Severity}

Severe ACS cases are complicated by acute respiratory distress syndrome (ARDS). This syndrome often presents with $\mathrm{PH}$, right ventricular dilation, and cor pulmonale in the most severe cases.

Increased right ventricular afterload as a result of in situ thrombi, fat embolism, pulmonary vasoconstriction, hemolysis, or worsening anemia is a major complication of ACS leading to poor outcomes. In a pediatric study of ACS, pulmonary embolism was the most common cause of death in ACS. As pediatricians commonly do not prescribe anticoagulants in ACS, there may be a danger of under-prescribing these medications in comparison to adult patients [74]. 
Markers of severe ACS include high LDH, a dramatic and sustained drop in hemoglobin, thrombocytopenia, elevated respiratory rate, extensive lobar involvement on lung imaging, $\mathrm{PH}$, and AKI.

\section{Catastrophic Sickle Cell Disease Syndrome}

SCD-related multiorgan failure (SMOF) or "catastrophic SCD syndrome" has been defined as the sudden onset of organ failures involving the lungs (severe ACS), liver, and/or kidneys [2, 75]. Clinical signs of this syndrome include a swift reduction in hemoglobin level and platelet count and shock (the most common cause of death in this syndrome) in the absence of a history of severe disease [2]. SMOF often overlaps with fat embolism and thrombotic microangiopathy syndromes, particularly in patients with a worsening presentation despite aggressive transfusion $[76,77]$.

\section{Respiratory Support}

The mode of respiratory support is critical in ACS cases. Mechanical ventilation is correlated with a high mortality rate during acute complications of SCD $[75,78]$. Instead, a protective ventilator strategy is suggested to protect the right ventricle as high mean airway pressures can worsen pulmonary hypertension which is commonly seen in ACS [79]. Guiding principles include limiting plateau and driving pressures with a low tidal volume and prone position and limiting positive endexpiratory pressure (PEEP) as much as possible [80, 81].

\section{Early Intervention Prevention}

While early transfusion shortens the duration and improves oxygenation in established ACS [82] and may even prevent ACS during VOC, delayed hemolytic transfusion reactions are particularly hazardous in a critical patient with ACS; therefore careful blood matching and indication for transfusion are required. This is explained further in the "Iatrogenic Concerns" section.

\section{Iatrogenic Concerns}

When a patient is deteriorating despite seemingly appropriate management, it is important to consider iatrogenic causes of worsening presentation. Reactions to particular medications and blood products can be catastrophic. 


\section{Toxic Side-Effects to Medications}

Opioid overdose in the critical care setting is possible during management of painful VOC. High doses of inconsistent levels of these drugs increase the risk of this outcome [83]. In cases of AKI, close attention to nephrotoxic drugs and antibiotics such as gentamicin is imperative. It is recommended to avoid antibiotics known to cause acute tubular necrosis of the kidney. Other antibiotics such as piperacillin/ tazobactam may cause drug-induced cardiac toxicity such as bradycardia [84]. Fluoroquinolones, ketolides, and macrolides predispose patients to a myriad cardiac toxicities including ventricular tachycardia and QTc prolongation [85].

\section{Delayed Hemolytic Transfusion Reaction (DHTR)}

DHTR arises when alloimmunization to RBC antigens or human leukocyte antigens occurs following transfusion. Patients of an older age, female sex, and clinical history of frequent transfusion and acute transfusion elevate the risk of this reaction [86-89].

The onset is variable often beginning $24 \mathrm{~h}$ to 21 days following a transfusion, and the presentation is insidious, often mimicking acute VOC [89]. Patients present with an acute drop in hemoglobin - a particular fall in HbA levels (evidence of donor RBC destruction), increased LDH, hemoglobinuria (a result of intravascular hemolysis), and relative or absolute reticulocytopenia. Diagnosis is often inconsistent. New RBC antibodies or a positive direct antiglobulin test are suggestive in combination with the clinical picture above [89].

Hyperhemolysis syndrome is a further complication of DHTR where the hemoglobin falls below the pre-transfusion level. Patients undergoing this reaction should not be transfused unless the anemia is life-threatening. An erythropoiesis-stimulating agent and intravenous iron may be helpful as well as an immunomodulatory therapy $[89,90]$.

\section{Conclusion}

The intensive care unit is the site of half of SCD-related deaths [91]. The high risk of mortality in this vulnerable population is often underappreciated by clinicians. Careful attention to detail and meticulous evidenced-based management of this unique population in the critical care setting have potential to improve outcomes.

\section{References}

1. Al Khawaja SA, Ateya ZM, Al Hammam RA. Predictors of mortality in adults with sickle cell disease admitted to intensive care unit in Bahrain. J Crit Care. 2017;42:238-42.

2. Hassell KL, Eckman JR, Lane PA. Acute multiorgan failure syndrome: a potentially catastrophic complication of severe sickle cell pain episodes. Am J Med. 1994;96(2):155-62. 
3. Platt OS, Brambilla DJ, Rosse WF, et al. Mortality in sickle cell disease. Life expectancy and risk factors for early death. N Engl J Med. 1994;330(23):1639-44.

4. Gardner K, Bell C, Bartram JL, et al. Outcome of adults with sickle cell disease admitted to critical care - experience of a single institution in the UK. Br J Haematol. 2010;150(5):610-3.

5. Vichinsky EP, Neumayr LD, Earles AN, et al. Causes and outcomes of the acute chest syndrome in sickle cell disease. National Acute Chest Syndrome Study Group. N Engl J Med. 2000;342(25):1855-65.

6. Jacobe SJ, Hassan A, Veys P, Mok Q. Outcome of children requiring admission to an intensive care unit after bone marrow transplantation. Crit Care Med. 2003;31(5):1299-305.

7. Darbari DS, Kple-Faget P, Kwagyan J, Rana S, Gordeuk VR, Castro O. Circumstances of death in adult sickle cell disease patients. Am J Hematol. 2006;81(11):858-63.

8. Berger S, Utech L, Fran HM. Sudden death in children and adolescents. Pediatr Clin N Am. 2004;51(6):1653-77. ix-x.

9. James TN, Riddick L, Massing GK. Sickle cells and sudden death: morphologic abnormalities of the cardiac conduction system. J Lab Clin Med. 1994;124(4):507-20.

10. Voskaridou E, Christoulas D, Terpos E. Sickle-cell disease and the heart: review of the current literature. Br J Haematol. 2012;157(6):664-73.

11. Caldas MC, Meira ZA, Barbosa MM. Evaluation of 107 patients with sickle cell anemia through tissue Doppler and myocardial performance index. J Am Soc Echocardiogr. 2008;21(10):1163-7.

12. Alpert BS, Gilman PA, Strong WB, et al. Hemodynamic and ECG responses to exercise in children with sickle cell anemia. Am J Dis Child. 1981;135(4):362-6.

13. Liu P, Olivieri N. Iron overload cardiomyopathies: new insights into an old disease. Cardiovasc Drugs Ther. 1994;8(1):101-10.

14. Buja LM, Roberts WC. Iron in the heart. Etiology and clinical significance. Am J Med. 1971;51(2):209-21.

15. Gladwin MT, Sachdev V, Jison ML, et al. Pulmonary hypertension as a risk factor for death in patients with sickle cell disease. N Engl J Med. 2004;350(9):886-95.

16. Johnson MC, Kirkham FJ, Redline S, et al. Left ventricular hypertrophy and diastolic dysfunction in children with sickle cell disease are related to asleep and waking oxygen desaturation. Blood. 2010;116(1):16-21.

17. Voskaridou E, Tsetsos G, Tsoutsias A, Spyropoulou E, Christoulas D, Terpos E. Pulmonary hypertension in patients with sickle cell/beta thalassemia: incidence and correlation with serum $\mathrm{N}$-terminal pro-brain natriuretic peptide concentrations. Haematologica. 2007;92(6):738-43.

18. Gordeuk VR, Castro OL, Machado RF. Pathophysiology and treatment of pulmonary hypertension in sickle cell disease. Blood. 2016;127(7):820-8.

19. Klings ES, Machado RF, Barst RJ, et al. An official American Thoracic Society clinical practice guideline: diagnosis, risk stratification, and management of pulmonary hypertension of sickle cell disease. Am J Respir Crit Care Med. 2014;189(6):727-40.

20. Barrett O Jr, Saunders DE Jr, McFarland DE, Humphries JO. Myocardial infarction in sickle cell anemia. Am J Hematol. 1984;16(2):139-47.

21. Bode-Thomas F, Hyacinth HI, Ogunkunle O, Omotoso A. Myocardial ischaemia in sickle cell anaemia: evaluation using a new scoring system. Ann Trop Paediatr. 2011;31(1):67-74.

22. Lippman SM, Niemann JT, Thigpen T, Ginzton LE, Laks MM. Abnormal septal Q waves in sickle cell disease. Prevalence and causative factors. Chest. 1985;88(4):543-8.

23. Mansi IA, Rosner F. Myocardial infarction in sickle cell disease. J Natl Med Assoc. 2002;94(6):448-52.

24. Khalique Z, Pavlu J, Lefroy D, Layton M. Erythrocytapheresis in the prevention of recurrent myocardial infarction in sickle cell disease. Am J Hematol. 2010;85(1):91.

25. Banerjee S, Owen C, Chopra S. Sickle cell hepatopathy. Hepatology. 2001;33(5):1021-8.

26. Hurtova M, Bachir D, Lee K, et al. Transplantation for liver failure in patients with sickle cell disease: challenging but feasible. Liver Transpl. 2011;17(4):381-92. 
27. Gardner K, Suddle A, Kane P, et al. How we treat sickle hepatopathy and liver transplantation in adults. Blood. 2014;123(15):2302-7.

28. Khalifeh HK, Chamoun CT, Elhoujairy AH, Alkoussa WA, Zeidan Lahoud CI, Masri GA. Acute hepatic crisis in sickle cell anemia: favorable outcome after exchange transfusion. J Hematol. 2016;5(4):138-41.

29. Brunetta DM, Silva-Pinto AC, do Carmo Favarin de Macedo M, et al. Intrahepatic cholestasis in sickle cell disease: a case report. Anemia. 2011;2011:975731.

30. Lacaille F, Lesage F, de Montalembert M. Acute hepatic crisis in children with sickle cell disease. J Pediatr Gastroenterol Nutr. 2004;39(2):200-2.

31. Ahn H, Li CS, Wang W. Sickle cell hepatopathy: clinical presentation, treatment, and outcome in pediatric and adult patients. Pediatr Blood Cancer. 2005;45(2):184-90.

32. Yawn BP, Buchanan GR, Afenyi-Annan AN, et al. Management of sickle cell disease: summary of the 2014 evidence-based report by expert panel members. JAMA. 2014;312(10):1033-48.

33. Lee ES, Chu PC. Reverse sequestration in a case of sickle crisis. Postgrad Med J. 1996;72(850):487-8.

34. Adamkiewicz TV, Abboud MR, Paley C, et al. Serum ferritin level changes in children with sickle cell disease on chronic blood transfusion are nonlinear and are associated with iron load and liver injury. Blood. 2009;114(21):4632-8.

35. Hassan M, Hasan S, Giday S, et al. Hepatitis C virus in sickle cell disease. J Natl Med Assoc. 2003;95(10):939-42.

36. Hasan MF, Marsh F, Posner G, et al. Chronic hepatitis C in patients with sickle cell disease. Am J Gastroenterol. 1996;91(6):1204-6.

37. Kato GJ, Gladwin MT. Sickle cell disease. In: Hall JB, Schmidt GA, Kress JP, editors. Principles of critical care. 4th ed. New York: McGraw-Hill; 2015.

38. Goodwin EF, Partain PI, Lebensburger JD, Fineberg NS, Howard TH. Elective cholecystectomy reduces morbidity of cholelithiasis in pediatric sickle cell disease. Pediatr Blood Cancer. 2017;64(1):113-20.

39. Vichinsky EP, Haberkern CM, Neumayr L, et al. A comparison of conservative and aggressive transfusion regimens in the perioperative management of sickle cell disease. The Preoperative Transfusion in Sickle Cell Disease Study Group. N Engl J Med. 1995;333(4):206-13.

40. Bauer TW, Moore GW, Hutchins GM. The liver in sickle cell disease. A clinicopathologic study of 70 patients. Am J Med. 1980;69(6):833-7.

41. Lama M. Hepatic abscess in sickle cell anaemia: a rare manifestation. Arch Dis Child. 1993;69(2):242-3.

42. Marolf MD, Chaudhary M, Kaplan SL. An hepatic abscess in a patient with sickle cell anemia. Pediatr Infect Dis J. 2016;35(11):1269-70.

43. Jitraruch S, Fitzpatrick E, Deheragoda M, et al. Autoimmune liver disease in children with sickle cell disease. J Pediatr. 2017;189:79-85.e72.

44. Markowitz RI, Harcke HT, Ritchie WG, Huff DS. Focal nodular hyperplasia of the liver in a child with sickle cell anemia. AJR Am J Roentgenol. 1980;134(3):594-7.

45. Ataga KI, Orringer EP. Hypercoagulability in sickle cell disease: a curious paradox. Am J Med. 2003;115(9):721-8.

46. Stein PD, Beemath A, Meyers FA, Skaf E, Olson RE. Deep venous thrombosis and pulmonary embolism in hospitalized patients with sickle cell disease. Am J Med. 2006;119(10):897. e7-e11.

47. Ataga KI, Key NS. Hypercoagulability in sickle cell disease: new approaches to an old problem. Hematology Am Soc Hematol Educ Program. 2007;2007:91-6.

48. Brunson A, Lei A, Rosenberg AS, White RH, Keegan T, Wun T. Increased incidence of VTE in sickle cell disease patients: risk factors, recurrence and impact on mortality. Br J Haematol. 2017;178(2):319-26.

49. Branchford BR, Mourani P, Bajaj L, Manco-Johnson M, Wang M, Goldenberg NA. Risk factors for in-hospital venous thromboembolism in children: a case-control study employing diagnostic validation. Haematologica. 2012;97(4):509-15. 
50. Sharathkumar AA, Mahajerin A, Heidt L, et al. Risk-prediction tool for identifying hospitalized children with a predisposition for development of venous thromboembolism: Peds-Clot clinical Decision Rule. J Thromb Haemost. 2012;10(7):1326-34.

51. Meier KA, Clark E, Tarango C, Chima RS, Shaughnessy E. Venous thromboembolism in hospitalized adolescents: an approach to risk assessment and prophylaxis. Hosp Pediatr. 2015;5(1):44-51.

52. Mahajerin A, Branchford BR, Amankwah EK, et al. Hospital-associated venous thromboembolism in pediatrics: a systematic review and meta-analysis of risk factors and risk-assessment models. Haematologica. 2015;100(8):1045-50.

53. Topley JM, Rogers DW, Stevens MC, Serjeant GR. Acute splenic sequestration and hypersplenism in the first five years in homozygous sickle cell disease. Arch Dis Child. 1981;56(10):765-9.

54. Emond AM, Collis R, Darvill D, Higgs DR, Maude GH, Serjeant GR. Acute splenic sequestration in homozygous sickle cell disease: natural history and management. J Pediatr. 1985;107(2):201-6.

55. Smith-Whitley K, Zhao H, Hodinka RL, et al. Epidemiology of human parvovirus B19 in children with sickle cell disease. Blood. 2004;103(2):422-7.

56. Airede AI. Acute splenic sequestration in a five-week-old infant with sickle cell disease. J Pediatr. 1992;120(1):160.

57. Bansil NH, Kim TY, Tieu L, Barcega B. Incidence of serious bacterial infections in febrile children with sickle cell disease. Clin Pediatr (Phila). 2013;52(7):661-6.

58. Asinobi AO, Fatunde OJ, Brown BJ, Osinusi K, Fasina NA. Urinary tract infection in febrile children with sickle cell anaemia in Ibadan, Nigeria. Ann Trop Paediatr. 2003;23(2):129-34.

59. Tsitsikas DA, Gallinella G, Patel S, Seligman H, Greaves P, Amos RJ. Bone marrow necrosis and fat embolism syndrome in sickle cell disease: increased susceptibility of patients with nonSS genotypes and a possible association with human parvovirus B19 infection. Blood Rev. 2014;28(1):23-30.

60. Ohene-Frempong K, Weiner SJ, Sleeper LA, et al. Cerebrovascular accidents in sickle cell disease: rates and risk factors. Blood. 1998;91(1):288-94.

61. Talahma M, Strbian D, Sundararajan S. Sickle cell disease and stroke. Stroke. 2014;45(6):e98-100.

62. Lee LJ, Kidwell CS, Alger J, Starkman S, Saver JL. Impact on stroke subtype diagnosis of early diffusion-weighted magnetic resonance imaging and magnetic resonance angiography. Stroke. 2000;31(5):1081-9.

63. Saposnik G, Barinagarrementeria F, Brown RD Jr, et al. Diagnosis and management of cerebral venous thrombosis: a statement for healthcare professionals from the American Heart Association/American Stroke Association. Stroke. 2011;42(4):1158-92.

64. Kassim AA, Galadanci NA, Pruthi S, DeBaun MR. How I treat and manage strokes in sickle cell disease. Blood. 2015;125(22):3401-10.

65. Hulbert ML, Scothorn DJ, Panepinto JA, et al. Exchange blood transfusion compared with simple transfusion for first overt stroke is associated with a lower risk of subsequent stroke: a retrospective cohort study of 137 children with sickle cell anemia. J Pediatr. 2006;149(5):710-2.

66. Howard J, Malfroy M, Llewelyn C, et al. The Transfusion Alternatives Preoperatively in Sickle Cell Disease (TAPS) study: a randomised, controlled, multicentre clinical trial. Lancet. 2013;381(9870):930-8.

67. Adams RJ, McKie VC, Carl EM, et al. Long-term stroke risk in children with sickle cell disease screened with transcranial Doppler. Ann Neurol. 1997;42(5):699-704.

68. Powars D, Adams RJ, Nichols FT, Milner P, Charache S, Sarnaik S. Delayed intracranial hemorrhage following cerebral infarction in sickle cell anemia. J Assoc Acad Minor Phys. 1990;1(3):79-82.

69. Mammen C, Bissonnette ML, Matsell DG. Acute kidney injury in children with sickle cell disease-compounding a chronic problem. Pediatr Nephrol. 2017;32(8):1287-91.

70. Lebensburger JD, Palabindela P, Howard TH, Feig DI, Aban I, Askenazi DJ. Prevalence of acute kidney injury during pediatric admissions for acute chest syndrome. Pediatr Nephrol. 2016;31(8):1363-8. 
71. Baddam S, Aban I, Hilliard L, Howard T, Askenazi D, Lebensburger JD. Acute kidney injury during a pediatric sickle cell vaso-occlusive pain crisis. Pediatr Nephrol. 2017;32(8):1451-6.

72. Yanni E, Grosse SD, Yang Q, Olney RS. Trends in pediatric sickle cell disease-related mortality in the United States, 1983-2002. J Pediatr. 2009;154(4):541-5.

73. Vichinsky EP, Styles LA, Colangelo LH, Wright EC, Castro O, Nickerson B. Acute chest syndrome in sickle cell disease: clinical presentation and course. Cooperative Study of Sickle Cell Disease. Blood. 1997;89(5):1787-92.

74. Mekontso Dessap A, Deux JF, Abidi N, et al. Pulmonary artery thrombosis during acute chest syndrome in sickle cell disease. Am J Respir Crit Care Med. 2011;184(9):1022-9.

75. Cecchini J, Lionnet F, Djibre M, et al. Outcomes of adult patients with sickle cell disease admitted to the ICU: a case series. Crit Care Med. 2014;42(7):1629-39.

76. Boga C, Kozanoglu I, Ozdogu H, Ozyurek E. Plasma exchange in critically ill patients with sickle cell disease. Transfus Apher Sci. 2007;37(1):17-22.

77. Chehal A, Taher A, Shamseddine A. Sicklemia with multi-organ failure syndrome and thrombotic thrombocytopenic purpura. Hemoglobin. 2002;26(4):345-51.

78. Allareddy V, Roy A, Lee MK, et al. Outcomes of acute chest syndrome in adult patients with sickle cell disease: predictors of mortality. PLoS One. 2014;9(4):e94387.

79. Mekontso Dessap A, Leon R, Habibi A, et al. Pulmonary hypertension and cor pulmonale during severe acute chest syndrome in sickle cell disease. Am J Respir Crit Care Med. 2008;177(6):646-53.

80. Boissier F, Katsahian S, Razazi K, et al. Prevalence and prognosis of cor pulmonale during protective ventilation for acute respiratory distress syndrome. Intensive Care Med. 2013;39(10):1725-33.

81. Vieillard-Baron A, Price LC, Matthay MA. Acute cor pulmonale in ARDS. Intensive Care Med. 2013;39(10):1836-8.

82. Mallouh AA, Asha M. Beneficial effect of blood transfusion in children with sickle cell chest syndrome. Am J Dis Child. 1988;142(2):178-82.

83. Lucas SM, Mason DG, Weyman D. A sickle crisis? A report of the national confidential enquiry into patient outcome and death (2008). London: NCEPOD; 2008.

84. Zaki SA, Lad V. Piperacillin-tazobactam-induced hypokalemia and metabolic alkalosis. Indian J Pharmacol. 2011;43(5):609-10.

85. Iannini PB. Cardiotoxicity of macrolides, ketolides and fluoroquinolones that prolong the QTc interval. Expert Opin Drug Saf. 2002;1(2):121-8.

86. McPherson ME, Anderson AR, Castillejo MI, et al. HLA alloimmunization is associated with RBC antibodies in multiply transfused patients with sickle cell disease. Pediatr Blood Cancer. 2010;54(4):552-8.

87. Rosse WF, Gallagher D, Kinney TR, et al. Transfusion and alloimmunization in sickle cell disease. The Cooperative Study of Sickle Cell Disease. Blood. 1990;76(7):1431-7.

88. Fasano RM, Booth GS, Miles M, et al. Red blood cell alloimmunization is influenced by recipient inflammatory state at time of transfusion in patients with sickle cell disease. Br J Haematol. 2015;168(2):291-300.

89. Vidler JB, Gardner K, Amenyah K, Mijovic A, Thein SL. Delayed haemolytic transfusion reaction in adults with sickle cell disease: a 5-year experience. Br J Haematol. 2015;169(5):746-53.

90. Bachmeyer C, Maury J, Parrot A, et al. Rituximab as an effective treatment of hyperhemolysis syndrome in sickle cell anemia. Am J Hematol. 2010;85(1):91-2.

91. Perronne V, Roberts-Harewood M, Bachir D, et al. Patterns of mortality in sickle cell disease in adults in France and England. Hematol J. 2002;3(1):56-60. 